Mike Sandbothe*

\title{
Interactivity - Hypertextuality - Transversality A media-philosophical analysis of the Internet ${ }^{1}$
}

\begin{abstract}
My considerations are organized into three parts. In the first part I expand upon the influence of the Internet on our experience of space and time as well as our concept of personal identity. This takes place, on the one hand, in the example of text-based Internet services (IRC, MUDs, MOOs), and through the World Wide Web's (WWW) graphical user-interface on the other. Interactivity, the constitution characteristic for the Internet, stands at the centre of this. In the second part I will show how the World Wide Web in particular sets in motion those semiotic demarcations customary until now. To this end I recapitulate, first of all, the way in which image, language and writing have been set in relation to one another in the philosophical tradition. The multimedia hypertextuality which characterizes the World Wide Web is then revealed against this background. In the third, and final, part I interpret the World Wide Web's hypertextual structure as a mediative form of realization of a contemporary type of reason. This takes place on the basis of the philosophical concept of tranversality developed by the German philosopher Wolfgang Welsch.
\end{abstract}

\section{Introduction}

In times of transition metaphors boom. And it is little wonder. For the metaphor, that is, the transfer from one semantic realm to another, is the linguistic instrument which allows us to grasp a transition as transition in words. The metaphor is an expression which in itself changes, that is,

1 Translation of a reworked and extended version of Mike Sandbothe: InteraktivitätHypertextualität-Transversalität. Eine medienphilosophische Analyse des Internet. In Mythos Internet, ed. by Stefan Münker and Alexander Rösler, Frankfurt a.M.: Suhrkamp, 1997, pp. 56-82.

* Mike Sandbothe

Friedrich-Schiller-University Jena

Philosophy Department

07740 Jena

e-mail:mike.sandbothe@uni-jena.de

homepage: http://www.uni-jena.de/ms. 
represents historical transition as a process of semantic transmission. In times of transition, in which concepts start to move along with the phenomena, hardly any linguistic instruments are more exact and appropriate than metaphors. But for metaphors, as for all words which we use, it is important that we understand the use we are making of them. If this occurs then metaphors can be applied discerningly to cast scientific light on complex phenomena. A metaphor is not per se imprecise or aesthetical; a concept not per se precise and scientific. In both cases the question of precision and scientific nature is a question of use. What I would like to attempt in the following is to mobilise metaphorically some expressions (such as 'space', 'time', 'identity', 'image', 'language' or 'writing') which we do not usually use as metaphors, so that they become suitable for the purposes of describing our dealings with the Internet.

Media shape our image of reality. This applies for media in the broad, in the narrow, and in the narrowest sense. By media in the broad sense I understand space and time as forms of intuition. They function as the constitutive media of our perception and cognition by making objects synthesizeable as identifiable entities. This insight lies at the root of the "Copernican revolution" with which Kant laid the basis of modern philosophy. Post-Kantian philosophy, from Hegel, Nietzsche, Heidegger, Dewey, Cassirer and the late Wittgenstein, through to Derrida, Goodman, Gadamer and Rorty has demonstrated that the strength of this foundation lies not - as Kant thought - in its transcendental signature, but far more in its flexibility, openness and changeability. Our spatiotemporal "ways of worldmaking" (Goodman, 1978) are not a rigid, uniform and ahistorical apparatus. The media of human construction of reality are shaped far more by pictorial, linguistic and textual sign systems which are historically contingent and culturally divergent.

Image, language and writing are what is meant when I talk of media in the narrow sense. They have been at the centre of many philosophical discussions in the twentieth century concerned mostly with identifying one or more of these media as being a binding base structure for human understanding of reality altogether, or - at the very least - as the foundation of the world-picture characteristic of Western culture. The spectrum reaches from analytic philosophy's "linguistic turn" (Rorty, 1967) and the diverse misunderstandings triggered by Derrida's early concept of a philosophical "grammatology" (Derrida, 1976) in the 
realm of post-modern thinking, through to contemporary proclamations of a "pictorial turn" (Mitchell, 1994).

Today it is becoming impossible to ignore the fact that neither media in the broad sense nor media in the narrow sense represent fixed, unchanging structures which offer a firm footing for philosophical theory. The way we deal with them is also dependent on institutional and technological developments which take place in the realm of media in the narrowest sense, that is, of technical media of transmission. This already holds for the influence which printed media, radio, and above all television have attained over our understanding of space and time as well as over our use of images, sounds and letters (Sandbothe/ Zimmerli, 1994). Given the influence that interactive data networks such as the Internet have on our perception and on our semiotic practice, the intertwined relationships existing between media in the broad, narrow and narrowest sense are becoming obvious. Space, time and identity are being inflected anew in the Internet. The traditional demarcation between image, language and writing is beginning to move. With interactive data-networks the digital revolution is becoming the driving force of a comprehensive transformation, one redefining the practices we use to handle signs and, hence, the bedrock of our understanding of reality.

In the following I shall look into this transformation process in three steps. In the first part I shall expand upon the influence of the Internet on our experience of space and time as well as our concept of personal identity. In the second part I will show how the World Wide Web in particular sets in motion the semiotic demarcations of image, language and writing. In the third, and final, part I interpret the World Wide Web's hypertextual structure as a mediative form of realization of a contemporary type of reason.

\section{Interactivity}

The Net opens up a new world to us. And this it does in a way differing from, say, a trip by car or aeroplane. When we fly from Berlin to San Francisco we also arrive in another world in which, partially, other laws dominate. But the basic coordinates of our understanding of reality space, time, identity - remain unchanged. It is different when we leave 'real' life and proceed into the Net. The world becomes 'virtual'. The 
constitution of reality becomes a different one. 'Virtual reality' steps in, taking the place of 'real life'. The terms 'real' and 'virtual' are reflexive terms similar to the opposition of natural and artificial (Welsch, 1997 , p. 172f). Things only ever appear 'real' or 'virtual' from a particular perspective. If one considers the oberver's relativity then it is no surprise that the on-line world already seems more real to many professional Net-surfers than the 'real' world outside of the Net. I do not associate normative implications of any kind with the real-virtual opposition. I use this only to differentiate varying forms of construction of reality from one another on the descriptive level.

\subsection{Identity in the Internet}

How does the virtual reality of cyberspace affect our concept of identity? To begin with, it seems, not at all. Since in the Net too I am usually out and about with my usual identity as the academic, Mike Sandbothe. I procure myself bibliographical information from the Library of Congress in Washington, make contributions to philosophical mailing lists to which I have subscribed, or confer with colleagues around the world via e-mail. At the same time, however, I also have the opportunity in the Net to set off to the anonymous channels of IRC or the fantasy environment of a MUD or MOO.

IRC is the abbreviation for Internet Relay Chat, which is a complex communications landscape consisting of a multitude of different conversation fora, or channels. People meet here on-line from all over the world, using nicknames they have chosen themselves, in order to converse with one another in the written form, but nonetheless synchronously, and to exchange up to the minute information on diverse themes. The subject areas range from day-to-day net gossip and virtual flirting, technical questions concerning hardware and software, through to more or less academic conversations on literature, politics, philosophy, physics, medicine and other objects (Rheingold, 1994, p. 176196). IRC was developed in 1988 at the University of Oulu (Finland) by Jarkko Oikarinen (Rheingold, 1994, p. 179).

MUD is the abbreviation for Multi User Dungeon, which is a virtual gaming 'haunt'. A number of different participants log in simultaneously in a fictional text-based game landscape in order to collect so-called 'experience points' in combat with other players and programmed 
robots, and to advance in the respective game's hierarchy to being a 'wizard' or 'god'. Wizards and gods have the power to alter the game landscape and to program the problems which the other participants have to solve (Rheingold, 1994, p. 145-175; Turkle, 1995, p. 180-186). The first MUD was created in 1979 by Richard Bartle and Roy Trubshaw at the University of Essex (Rheingold, 1994, p. 151).

MOO stands for Multi User Dungeon Object Oriented, which - in contrast to the strictly hierarchically organized and sometimes quite violent adventure MUDs - are games in which cooperation, solidarity, education and science are central. Every participant receives programming rights from the start, i.e. he or she can create rooms and objects and independently contribute to the shaping of the game landscape. It was James Aspnes, a graduate student at the Carnegie Mellon University in Pittsburgh, who, in 1989, came up with the idea of conceiving such democratic MUDs and thus foregrounding the development of virtual communities. In the USA MOOs have been being used for several years as interactive learning environments in which parents and children, pupils and teachers can together playfully gather experience with the new medium Internet (Bruckman, 1997a/b).

In IRC, in the MUDs and MOOs I can present myself with an invented identity $\mathrm{X}$ or $\mathrm{Y}$ according to the context. Of course, I could also do this "in real life" - or, to use the Internet-jargon abbreviation, IRL - in some bar or other. But limits are imposed on me by my appearance, my gender, my physical and social identity. This is not the case in the Net. In the Net, the day-to-day concept of physical and embodied identity is rendered void. What is interesting in this is that there are fluid transitions between the normal Net-world of daily academic life and invented MUD, MOO and IRC identities. As such the IRC command 'whois', for example, makes it possible to relate the different nicknames of a user, who might be sojourning in several channels simultaneously, to his or her e-mail address, host and user IDs. But it should be borne in mind here that most Net freaks use several e-mail addresses and user or host IDs. The supposedly 'real' user and host identities can also be de facto virtual, that is, different from the user's IRL identity and IRL location.

Many MUDs and MOOs are based on the permanent interplay between real and virtual identities. Thus in the MIT MediaMOO close entanglements and frequent transitions between players' academic and 
fictional identities are the norm. The MediaMOO is a text-based communications and research environment for media researchers. It was set up at the end of 1992 by Amy Bruckman, a former doctoral student at the MIT MediaLab teaching now at the Georgia Institute of Technology, and has been accessible to the Internet public since the start of 1993. In December 1994 MediaMOO already had 1100 active members from 29 countries (Bruckman/Resnik, 1995). In 1996 a didactically conceived and educationally supervised virtual school-landscape - the MOOSE Crossing - was opened on the MIT computers for 800-1000 children aged from 10 to 12 years. This project is also being led by Amy Bruckman (Bruckman, 1997a/b). On the title page of her publications the young Internet researcher provides, alongside her IRL name, the email addresses of the fictional identities by which she is known in different places on the Net where she has carried out investigations and interviews for her research. In so doing she makes it clear how closely intertwined the different identities are with one another and how just this mesh of identities can be deployed for academic research (Bruckman, 1992). But it is not just the traditional concept of personal identity, but the everyday experience of space and time underlying this concept which is transformed by the virtual Net-world.

\subsection{Space and time in the Internet}

As a cursor-identity I move quite independently of the real world and its geographical distances. I move in the Net's digital space and beam myself from continent to continent without any role being played by real separation (Mitchell, 1995). As such, even when I am out and about in the Net with my normal academic's identity, I still find myself in virtual mode. In cyberspace everything is present here and now. This leads to change in our experience of time (Sandbothe, 2000a). On IRC, in the MUDs and MOOs there is no night. It is always day. Somewhere in the world people are always awake to populate the Net's countless meeting places. The screen only knows how to glimmer. The virtual world is independent of sunlight. There is no unitary, somehow natural time which partners in communication could presuppose as self-evident. Rather they must onerously inform one another about their respective local times and adjust for the differences if they want to meet on the Net. The horizons of time are in constant motion. 
Whereas television prescribes its recipients a fixed linear time track, the timing, that is the temporal arrangement of on-line meetings in MUDs and MOOs takes place through individual agreements between users. Here too, of course, certain regularities in practice quickly establish themselves. But these regularities are appointments you make yourself, which can be made the object of dealings and discussion within the Internet's virtual communities. In place of a prescribed presence, conveyed to passive recipients by the medium of television, come in the Internet's communication services socially constructed times of presence, within which users constitute their identities on the bedrock of writing-based interaction in a context of shared plans for the future.

Furthermore, in the virtual surroundings of text-based communications worlds users themselves have the chance to invent and to program the narrative description of the virtual space in which they, along with other participants, move. Space no longer seems to be a given entity, within which you simply move around passively and on which you can have no influence whatsoever. Rather it becomes a consciously constructed and aesthetically staged artefact. Along with the rooms around which on-line agents move, the times in which respective narratives are played out are also staged by the participants themselves. The peculiar virtual spatiality of MUDs and MOOs corresponds with their specific temporality.

Unlike with television or computer games designed for stand alone machines, the inhabitants of the Internet's communicative, text-based worlds of MUD and MOO are not forced into prescribed simulations of space and time, but rather experience space and time as creatively shapeable constructions of their narrative and cooperative imagination. In MUDs and MOOs a theatricalization of space and time takes place. Participants who have and make use of programming rights become the architects and dramaturgists of a virtual theatre, on whose electronic stage the spatio-temporal base structure of our perceptions itself becomes the object to be staged.

\subsection{Interactivity in the mode of appresence}

Until now I have gone into changes relevant not primarily to the World Wide Web, but to text-based Internet services such as IRC, MUDs and MOOs. I shall now concentrate on the specific features of the World 
Wide Web. To do this it is helpful to compare the media structure of the Internet with those media which have decisively forged our daily life until now: with television and the telephone. Whereas television can only be described as a one-way street in terms of its communicative structure - information flows unidirectionally, exclusively from the broadcasting institution with its programme mandate to the passive TV consumer - the Internet is an interactive and multidirectional medium. Every receiver is a potential transmitter. Yet this already holds for traditional text-based services like IRC, MUDs and MOOs. The World Wide Web's specificity consists in that these systems' simple interactivity is decisively enhanced and fashioned by the World Wide Web's graphical interface.

Everyone who has a PC, an Internet connection, the corresponding software, and perhaps in addition access to a (video) camera and a scanner, can design their own multimedia Web pages in the World Wide Web, can devise and make available their own programme. Of course it is possible to create pages for each of the varying real and virtual roles which you play within and without the Net (Turkle, 1995, p. 258f). These can be intertwined with one another through hyperlinks. In the same way networked links can be made with the Web pages of cybernaut friends and with every other data provider to be found on the Net.

The flexible transition from the position of recipient to transmitter and the possibility of individual programme design are familiar to us from the structure of ordinary conversational situations. The telephone, which reproduces these situations over spatial distances, is already an interactive technology in this sense. In telephone communication we choose our partner in communication ourselves and, by contributing to the conversation, assume influence over the 'programme' in a figurative sense. But, with the exception of telephone conferencing, the telephone's bidirectional communicative structure is limited in relation to the Internet's multidirectionality. Furthermore - if you neglect answering machines - the auditive telephone medium, bounded to the human voice, permits no self-presentation which is independent of one's own presence. It is exactly this which becomes possible through the World Wide Web.

My Web page is a miniature double of my self, in some cases even the creative invention of a new self, of a new identity, which I had previously hidden from myself and others, and which now mediatively 
interacts with other people in my absence. The particularity in the World Wide Web's media structure lies not least in this new dimension against telephone and television, that of a so to speak 'appresent' interactivity independent of my real presence. Through this our identity is pluralized in its rudiments. The images we have of ourselves and which others have of us gain a life of their own independent of our presence. These plural identities stand in intertwined relations with other real and virtual Net identities which we act under in different contexts on the Net. Our Net personality is composed of a mesh of varying roles, identities and functions, which we can strictly isolate from one another, or consciously link with one another. The technical possibility of these entanglements results from the second specific feature of the World Wide Web: from hypertextuality.

\section{Hypertextuality}

Whereas the classical Internet services, from e-mail and Talk, Net News and mailing lists, through to IRC, MUDs and MOOs are oriented towards the model of linear textuality, the qualitative transition to nonlinear hypertextuality occurs in the World Wide Web. The word 'hypertext' was coined by Ted Nelson in the sixties. In his "Xanadu Hypertext System" he was one of the first to attempt the technical implementation of the hypertext concept (Nelson, 1981). But Douglas C. Engelbart was the first to successfully achieve this goal with his oN Line System (NLS) in 1968. The idea of hypertextuality in a broad sense can be traced back to Vannevar Bush. This early pioneer of associative information retrieval had already projected a new, technically advanced architecture of scientific thought and research in his article "As We May Think" which appeared in Atlantic Monthly in July 1945. The "Memex system" he designed was conceived as a mechanical apparatus which, through "associative indexing", should make it possible that "any item may be caused at will to select immediately and automatically another" (Bush, 1945, 34).

Hypertext documents, which constitute the core of the World Wide Web can be structured by means of the simple HTML language (HyperText Markup Language) so that the text represents not a fixed linear sequence, but functions as a network to be actively composed. Every building block of text (node) contains a multitude of keywords, pictograms and pictures which can be clicked on with a mouse: these are the 
so-called "links". These easily set up and flexibly variable points of intersection bind the nodes into a rhizomatic network.

Hypertext technology has profound effects on the writing and reading of texts (Landow, 1992). In hypertextual conditions writing and reading become pictorial operations. The writer develops a netlike framework, a rhizomatic image of her thoughts. This image is multiform and complex. It consists in a plurality of varying paths and references which the reader forms into new thought images resulting from interplay between the text's open structure and the reader's interests and perspectives. Equally, in the hypertext medium the writer is no longer in a position of omniscience. Whereas the traditional author is responsible alone for sketching out the closed system of the book or essay he writes, hypertextual writing and thinking can take place in immediate interaction with other people's writing and thinking. Since in principle every file available in the Internet can be integrated into one's own writing the opportunities for interaction are endless. The reference system is limitless. You could say that the World Wide Web as a whole is a single giant hypertext in a state of permanent change, in constant motion.

Through the World Wide Web's hypertextual data mesh it becomes possible to mirror directly the dynamics of knowledge transformation which characterize modern science. The medium of books and the associated publishing institutions have long been unable to come to terms with the exponentially climbing dynamics of knowledge. The time elapsing between the writing of a text and its publication by the publishers amounts to several months or even years. This gap in time is overcome by immediate publication in the Net. It is even possible to work on a book or an essay in the Net itself. Even the creation of the text then takes place in a public mode, i.e. in close cooperation with other Net users who contribute with their comments to the work in progress.

The World Wide Web doesn't make hypertextuality obligatory. The book's linear structures can be depicted straightforwardly in the World Wide Web. What is more, most texts currently found in the Net are not hypertexts, but completely normal essays and books which have been converted into HTML code and revised a little for the Net. At the moment the World Wide Web serves predominantly to make books and essays more accessible more rapidly. So, for a philosopher who is familiar with the Internet, it is no longer a problem to get hold of works by 
John Locke, Immanuel Kant, Friedrich Nietzsche or Ludwig Wittgenstein on screen or to view the papers published in the Net from conferences which he considers important.

In contrast to this the authentic hypertext-style writing and thinking measuring up to the features of the new medium still represents a demanding future task. Schools and universities, teachers, academics and authors must first of all be prepared for this (Sandbothe, 1996b, 1999, 2000b). For this purpose it is to be expected that classical texts of the tradition be made available as genuine hypertexts, i.e. as thought networks bound together by links (cf. Delany/Landow, 1991, p. 185ff). This is not as revolutionary and extraordinary as it seems at first glance. Ancient texts, which we today naturally read in book form already have a similar media transition behind them. They were originally written on papyrus rolls, without punctuation, page numbers and contents pages, and were first implemented in book form afterwards (Reynolds/Wilson, 1978; Bolter, 1991, esp. Chapter 6).

The pragmatic restriction, thematic and goal-directed structuring of textual and pictorial elements of the World Wide Web is achieved through user activity. The user's creativity constitutes the referential framework which provides answers to questions which had been posed before Web browsing began. Through the application of Net search robots, i.e. automatic index programs like Excite, Altavista, InfoSeek, Lycos, Hotbot or Northern Lights, which is quickly learned, as well as the use of archiving and structuring tools such as Bookmarks and Hotlists the Net newbie, first threatened with being 'lost in cyberspace', in time becomes a sovereign Net navigator.

The Net navigator, or cybernaut, has learned to find her way around in the rhizomatic flood of hypertext links. She knows that there is no original text, no 'authentic' document to which all other documents are to be related. She has figured out that on the Net it is, above all, a matter of forming little machines, creative text formations and meaningful images of thought out of the manifold and dispersed textual nodes. These machines, formations and images, which didn't exist previously in this manner and will not continue to exist in the future, constitute a new ontology of hypertextual signs, one which transforms our basic semiotic concepts. In order to work out what these semiotic changes are, it is helpful to remind ourselves first of all of the classical distinctions which have determined our dealings with signs until now. 


\subsection{The classical triad: image, language, writing}

Traditionally in philosophy language and writing, as abstract and arbitrary sign systems, have been contrasted with images, as a concrete and natural medium for representation (Rollin, 1976). In this images are afforded a peculiarly ambivalent status. On the one hand, in the tradition reaching from Plato to Hegel, they appear as "an imitation of looks" (Platon, 1968, p. 281 [598b]), that is as intensified appearance. The media of language and writing, thought to be more resistant to mere appearance, are contrasted with the apparent image. On the other hand the image functions in the mainstream of Western tradition, in which cognition is thought of as representation and truth as adequaetio, as a positive exemplar. This was shown critically by Heidegger (Heidegger, 1977). Language has been interpreted ever since Aristotle as a tool for the arbritrary designation of mental images (ideas) representing reality which "are the same for all" (Aristotle, 1994, p. 43 [16a]). Correspondingly, writing came to be degraded as a tertiary supplement. It served, according to this tradition, to materialize the phonological signs of spoken language and to make them storable. The ideal to which language and writing are therewith subjected in equal measure is the procedure of adequate, neutral representation derived from the model of images. Where language and writing are unable to fulfil this ideal they drift into a position exposed to the suspicion of deception, a position occupied by the image in book X of Plato's Politeia. Jacques Derrida in of Grammatology unveils and attempts to deconstruct this constellation.

In recent debates prompted by Derrida, Goodman, Rorty and others, images are no longer apprehended as being demarcated from signs, but as sign systems in themselves, to be analysed according to the model of language and writing. Frequently, however, certain traditional presuppositions are adhered to. So, for example, it is usually assumed that the difference between linguistic, textual and pictorial signs is a difference founded in the semantic and/or syntactical structure of the respective system of signs. A position of this type is advocated, taking up Goodman's argument, by Oliver R. Scholz (Scholz, 1991, p. 82-110). These assumptions contrast with the thesis, going back to the late Wittgenstein, that a sign is first defined through its usage as a image, as a sound or as a letter (Wittgenstein, 1953). It is insisted by various authors, however, that even in conditions of a usage-theory of signs there be a unita- 
ry way of applying something as image, as language or as writing. At the base of this view is the idea that certain features of the usage can be named which distinguish 'image games', 'language games' or 'writing games' as being image games, language games or writing games. These general features are to permit the internally unitary definition of the varying sign games and the clear division of the different sorts of sign from one another through a usage theory of signs (Novitz, 1977; Kjorup, 1978).

One must object to this that a consistent execution of a pragmatic usage theory of signs would indicate that we have to deal with complex bundles of image, language and writing games which too will exhibit no unitary feature common to all elements of the respective set. The metaphor of "family resemblances" (Wittgenstein, 1953, p. 32 [\$67]) was introduced by Wittgenstein to describe complex entangled relationships of this type. In addition to the internal entanglement of image, language and writing comes the external entanglement which determines the relation of the three sorts of sign to one another. Just as a general essential feature cannot be identified to define image as image, language as language, and writing as writing, no firm dividing lines can be fixed between the different types of sign. Pictures, sounds and letters are always intertwined or demarcated relative to and dependent on media in the narrowest sense, which set out the framework of their use. The previous media system, in which audiovisual and print media were clearly divided from one another suggested strict demarcation between the sorts of sign. The World Wide Web's multimedia mesh of signs does away with this separation and redefines their relations (Sandbothe, 1996a).

\subsection{Digital Entanglements}

Before I begin talking about the mesh of image, language and writing which characterizes the World Wide Web, I would like first to come back to the text-based Chat programs (IRC, MUDs, MOOs). Chat programs developed independently of the World Wide Web but are increasing being integrated into the Web. In Chat programs writing functions as a medium of direct synchronous communication between conversation partners who are physically separated and who, as a rule, have never seen each other. The anonymity specific to the textual medium of the book is connected in "Chat" with the synchronous interactivity and 
immediate presence of the conversational partner characteristic of spoken language in face to face communication. In Chat's "Computer Mediated Communication" features which previously served as difference criteria for the distinction between language and writing are becoming entangled. Elisabeth M. Reid examined in detail how the "sharp distinction between the spoken and written word" (Reid, 1992, p. 7) becomes blurred in Computer Mediated Communication. The traditional distinction of spoken language as a medium of presence is undermined by the 'appresent presence' of the participants in the written conversation of on-line Chat. It is this performative writing of a conversation in which language is interactively written instead of spoken, that I call the tendency toward scriptualization of language.

Corresponding to this, as a parallel phenomenon, is a tendency toward the verbalization of writing. The medium of writing is used in the conditions of book printing as a distributive technology which excludes immediate interaction between sender and receiver. In contrast, the Internet opens up possibilities for usage through which writing can be deployed as a medium permiting constant switches in position between sender and receiver in a flexible manner, similar to that of spoken conversation. It is this language-like, that is reciprocal, usage form of an interactively used writing in conversational mode which I call the tendency toward verbalization of writing.

The parallel nature of the two transformation tendencies toward scriptualization of language and verbalization of writing indicates that neither of the two referents - neither spoken language nor writing remains unaltered. In on-line Chat language functions as writing, that is, the spoken word realizes itself in writing as a sign of a sign. And at the same time writing functions in on-line Chat as an interactively modelable and contextually situated writing of language, that is, the written word is no longer misinterpreted as the sign of an authentic sign - with the latter itself being no longer sign-like. Instead it is understood as being the sign of a sign of a sign and so on, i.e. as an unending semiotic process with a pragmatically determined relative end. Thus in the medium of Internet a far-reaching, internal development in philosophy becomes explicit and manifest, namely that which Josef Simon, following on from Derrida, systematically developed in his Philosophy of the Sign (Simon, 1995) and situated historically within the framework 
of a "process of inversion" (Simon, 1995, p. 43) of the semiotic thinking of occidental philosophy.

The consequences for semiotics which result from the cultural practices arising in the World Wide Web as a whole are more complex than the effects just described in the realm of Chat programs. On the one hand, in that the World Wide Web incorporates text-based Chat, it picks up the usage of writing in analogy to spoken language these services make possible. On the other hand, however, in that the World Wide Web is characterized by hypertext documents, writing is reorganized in a new way pictorially. Alongside the scriptualization of language and the verbalization of writing taking place in communications services, there are in addition two transformational tendencies which are specifically characteristic for the hypertextual World Wide Web:

\subsection{The Pictorialization of Writing and the Scriptualization of the Image}

I will begin with the first of the two named tendencies: the pictorialization of writing. It is expressed in both the graphic handling of phonetic writing and in the rehabilitation of non-phonetic writing. Both aspects of the pictorialization of writing were anticipated by Jay David Bolter in his 1991 book Writing Space. The Computer, Hypertext, and the History of Writing. Attention is drawn to the first aspect - the pictorial use of phonetic writing - by Bolter when he points out that the use of automatic structuring programs within the framework of word processing has the effect of making "text itself graphic by representing its structure graphically to the writer and the reader" (Bolter, 1991, p. 26). The World Wide Web's networked hypertextual system radicalizes this tendency towards the pictorialization of writing, one already fundamentally inset within electronic writing.

In hypertextual conditions writing and reading become pictorial operations. The writer creates a net-like structure on the screen, a rhizomatic image of his thoughts. This image is many-sided, associative and complex. It consists of a plurality of different paths and references which the reader forms into individually varying textual images, resulting from the interplay between the text's open structure and the interests and perspectives of the reader. Hermeneutic operations and interpretory processes, which in reading a printed text take place in the 
reader's mind alone, become visible in hypertextual conditions as reading tracks which in navigated reading contribute to the constitution of the text on a software level. The entire hypertextual mesh of icons, digital images, audio and video sequences, as well as linear and non-linear texts can, against this background, be metaphorically described as an image-like structure, i.e. as a textual image or a text image. The situation of the text in space, the tactile distinction of individual complexes of signs as clickable links, the variably formable structure of the text's background, or the opportunities provided by Java to set letters in motion and embed them in graphic scenes - these are all aspects of what, in summary, I call the pictorialization of phonetic writing.

The second aspect of the pictorialization of writing - the rehabilitation of nonphonetic writing - had also been identified by Bolter in his 1991 book as a fundamental feature of electronic writing space. Using the example of the Apple Macintosh Desktop he makes clear that icons function as "symbolic elements in a true picture writing" (Bolter, 1991, p. 51). And he continues: "Electronic icons realize what magic signs in the past could only suggest, for electronic icons are functioning representations in computer writing" (Bolter, 1991, p. 529). The World Wide Web also radicalizes this aspect of electronic writing. In the Web text and image signs become programmable as icons, that is, as signifiers, which on the pragmatic level with the click of a mouse produce no longer a merely symbolic, but a real link to what they signify. So in a philosophical hypertext, for example, a click of the mouse on a sequence of words "Nietzsche's 'Genealogy of Morals" programmed as a link leads me directly to Nietzsche's text; or an image of Friedrich Nietzsche programmed as a link takes me directly to a Web page with information about the philosopher's biography.

Bolter himself, in his essay The Internet in the History of Writing Technologies (Bolter, 1997), made use in his semiotic analysis of the World Wide Web of the possible extensions, which follow from his 1991 book. In doing this, however, he arrives at a different assessment on some points. On the one hand he elicits with great clarity the way in which hypertext in the World Wide Web "is first produced in a process of rearrangement between the reader and the (absent) author(s) who built the corresponding links into the text" (Bolter, 1997, p. 43). On the other hand he emphasises that for the relationship between image and writing: "All the same, the distinction between word and image does 
not break down completely in electronic writing. Or, better, the distinction collapses - only to confirm itself once again anew" (Bolter, 1997, p. 54).

Bolter is surely right when he emphasises that in the World Wide Web the difference between word and image doesn't break down completely. Of course the accustomed difference between image and writing is retained on the surface of our perception of signs. In the World Wide Web too we are able to discern by means of our well-established semantic frame whether we are dealing with graphic or text signs. What is changing, however, is the whole spectrum of possible use which we can make of image and writing in hypertext. Alongside linear sequences of writing non-linear meshes of text are found, alongside simple, non-clickable images there are image-intersections functioning as 'source anchors', which refer with a link beyond themselves to other signs. The semiotic difference between image and writing neither breaks down completely, nor does it remain stiff and unaltered: rather it constitutes itself anew in the context of a medium-specifically altered usage, i.e. it formulates the semantic distinction it makes in a modified manner and accentuates aspects different from those emphasised until now.

On the level of use our dealings with writing in hypertextual conditions are beginning to adopt qualitites and aspects which we traditionally assigned to images. The floating reading of text signs is being modified by an image-like dramatization of the arrangement of signs which is characteristic of the World Wide Web. In digital writing hypertextual links function as intersections which cut across an individual text's linear flow of signs and present themselves as nodes of thought, giving the reader the opportunity whilst reading to codesign actively the individual constellation of the text, i.e. the sequence of textual elements and the direct link to inter-, para-, meta- and hypotexts. In this open, non-linear mode of floating reception of signs forms of perception enter in which are known to us from the reception of images. In the perception of a picture - unlike the reading of a book - we are not tempted from the start to follow a linearly sequenced pattern of thought-construction. The pictorial elements comprising an image are susceptible instead to various patterns of non-linear reception and hence different forms of reading and of construction of the image as a meaningful unity. 
New modes of use and practices in usage which effect our dealings with images are also taking shape in hypertextual cyberspace. In the World Wide Web, however, images often still function according to the traditional pattern as a kind of quasi-reference. They interrupt the flow of links and represent artificial end points of menus, i.e. impasses in hyperspace. These referential modes of usage of images is what Bolter has in mind when he writes: "The naive belief in the directness of the image has a long history, the traces of which can be followed from the discovery of perspective painting through to the present day. Today too even the most refined observer of the World Wide Web can be tempted to forget the complex character of a Web page, so as to concentrate on the static or moving image as a direct representation of reality" (Bolter, 1997, p. 54f). Following Bolter one would have to talk more or less pejoratively of a picturalization of writing in the sense that the relevance of language and writing is being visibly undermined by the dominance of images.

But Bolter does not leave things with this negative scenario. He alludes, in addition, to the possibility of a picturalization of writing which leaves neither of the two sign systems unaltered. Thus at the end of the essay already quoted Bolter emphasizes: "The illusion of presence will exist in the Internet alongside more imaginative and intelligent forms of hypertextual communication in which word and image interact with one another in a self-referential manner." (Bolter, 1997, p. 55) This kind of transmedial interaction, through which both referents undergo an inner transformation, becomes visible when one thinks of the picturalization of writing along with the tendency toward scriptualization of the image which is bound up in this.

Just as the images which play a dramaturgical role on stage in a theatre production are not viewed by the audience as images in isolation, but as images which depict images, pictorial signs on the digital scene of the Internet are able to function as references which are bound into the concrete action-space of the pragmatic Net-use event. I call this pragmatic decoupling of the image from its representational function the scriptualization of the image. When we read textual signs we do not read each letter and each word as something which stands in some kind of similarity relation to something outside of language. Instead, when reading, we allow ourselves to be referred from one letter to the next, from one word to the next, from one sentence to the next, an so on. Such 
a floating form of reading is also establishing itself in the World Wide Web in dealings with pictorial signs. We read the image as a sign which refers to other signs not only semantically, but also and above all pragmatically, i.e. with a straightforward mouse-click.

If you consider not only the external scriptualization of the image but also the internal data structure of digital images, then it becomes clear that the images composed of pixels have textual character as a result of their technological structure. With the corresponding editor programs, the elements comprising a digital image can be exchanged, moved and altered just as written characters can. In this way images become flexibly editable scripts. In the digital mode the image loses its distinguished status as a representation of reality. It proves itself to be an aesthetic construction, a technological work of art whose semiotics result internally from the relations of pixels and externally through the hypertextual references to other documents (Mitchell, 1992).

It is surely meaningful and important in semiotic and media-theoretical analyses to consider also the persistent force of well-established meanings of terms like 'image', 'language' and 'writing'. But in order to understand suitably the ongoing transition from the old modes of usage to new ones, it is necessary, in addition, to mark out terminological shifts which might in future determine the 'actual' meanings of the terms in question. This can be achieved by trying to trace on a semantic level the changes taking place on the usage level through a methodological metaphorization of our dealings with the expressions 'image', 'language' and 'writing'. By this I mean an anticipatory procedure which will enable us to describe predictively the changes in meaning and perception which are taking shape. Media-pragmatic and mediapolitical fields of application simultaneously open up for such a futureoriented analysis, one opposing the traditional understanding of theory which stipulates that academic inquiry be an archeological reconstruction of things past. The Internet's current development to being a mass medium, which is beginning to shape the communications behaviour and information practices of modern society beyond the realm of the academic elite (Morris/Ogan, 1996), marks out the largely open space of a micropolitics of the sign: a semio-political space in which it will be decided which dimensions of the new mass medium Internet are made accessible to people and which will not. The concept of transversality 
can serve as a philosophical guideline for such micropolitics of the sign (Sandbothe, 1998).

\section{Transversality}

The philosophical concept of transversality has long been familiar within mathematics and geology (Welsch, 1995a, p. 367-371). It was first used in a philosophical context by Jean-Paul Sartre and was first coined as a philosophical term by Gilles Deleuze and Félix Guattari. The application to the theory of reason and the systematic extension into an edifice of thought was performed by Wolfgang Welsch in two steps. A first draft of the concept of "transversal reason" was set out by Welsch in Chapter 11 of his Unsere postmoderne Moderne (Welsch, 1987). The systematic elaboration followed in Vernunft. Die zeitgenössische Vernunftkritik und das Konzept der transversalen Vernunft (Welsch, 1995a; cf. $1998 \mathrm{a} / \mathrm{b}$ ). What are the basic ideas of Welsch's theory of transversal reason, and how can they be related to the media transformations of our understanding of reality described in the first two parts of the current essay?

To answer this question I shall concentrate on the systematic account developed by Welsch in the second part of his book on reason under the title Transversal Reason. I shall not consider here the question of the relation between this account and Welsch's outline in his book on the postmodern (cf. Welsch/Sandbothe, 1997). To begin with it should be highlighted that Welsch develops the concept of transversal reason without consideration of media philosophical issues. My interpretation strategy results from this fact. It follows the pattern used by George P. Landow to interpret Derrida in his book Hypertext. The Convergence of Contemporary Critical Theory and Technology, and which he described as follows: "[...] something that Derrida and other critical theorists describe as part of a seemingly extravagant claim about language turns out to describe the new economy of reading and writing with electronic virtual, rather than physical forms" (Landow, 1992, p. 8). From early on Welsch had - unlike Derrida - emphasized the "exoteric" character of postmodern thinking (Welsch, 1987, p. 202-206). What links him, however, with Derrida in terms of electronic writing is the fact that Welsch too has not explicitly thematicized the connection between the constitution of reason he describes and the media conditions which make this reason possible and come to light in digital networks. Welsch presented 
a first analysis of the Internet in his essay Information Superhighway or Highway Number One (Welsch, 1995b). He does not, however, establish here a direct relationship to the concept of transversal reason.

The central ideas of Welsch's concept of transversal reason can be summarized with three basic theses. Firstly, the constitution of rationality is characterized by an ineluctable disorderliness. Secondly, reason is in principle capable of reconstructing and describing precisely this disorderliness. Thirdly, it is only when reason productively analyses the subconscious entanglements of rationalities that it will be suitably equipped to solve contemporary problems. The first thesis is directed against the idea, dominant from Kant through to Habermas and Lyotard, that reason is concerned with an orderly framework of rationality types clearly divided from one another. The second thesis opposes the danger of diffusion which has led, especially in the setting of posthistorical thinking, but also with some postmodern philosophers, to a position of arbitrariness and of 'anything goes'. The third thesis makes it clear that applied and problem-oriented philosophy must in no way amount to a simple application of abstract philosophical models to reality. In its pragmatic and transversal version it is capable of reflexion about those constellations of rationalities which are effective practically and which are already determined in their inner by contingent realities.

All three theses can be illustrated with the aid of the interactive hypertextuality of the World Wide Web. In doing this I take as my guide the assumption that the World Wide Web is a medium in which the - for the book culture, subconscious and hidden - disorderliness of rationality which Welsch dealt with comes explicitly to light. First of all, however, it is important to append a distinction which is central to the understanding of Welsch's basic theses. It is explained by Welsch in the Introduction to the second part of his book. I mean the distinction between rationality and reason. In recourse to the Kantian distinction between understanding and reason Welsch defines reason as that faculty whose task it is to reflect upon the relationship between different types of rationality (Welsch, 1995a, 437f).

The first of the three basic theses relates to the relationship between rationalities. To begin with it leaves aside the issue of reason in the sense of a faculty of reflexion which goes beyond these. The relationship between rationalities is defined by Welsch as "rational disorderli- 


\section{2}

ness" (Welsch, 1995a, p. 447). Whereas, from Kant through to Habermas and Lyotard, the framework of rationalities has been conceived of in a way guided by the book, namely as a relational framework of separate, in themselves autonomous chapters (Kant, Habermas) or aphorisms (Lyotard), Welsch, in recourse to Derrida and Deleuze, compares "the real consitution of rationalities" (Welsch, 1995a, p. 448) with "moving and changing, net and web-like architectures" (Welsch, 1995a, p. 943). Welsch shows in detail that the classically ordered framework of cognitive, aesthetic and moral-practical rationalities is a superficial phenomenon. A contingent network of "family resemblances" (Welsch, 1995a, p. 534ff) between different paradigms and alliances of paradigms form the fundament for this. The maxim for rationality theory resulting from this is to uncover "the whole traffic system of both the horizontal and the vertical connections" (Welsch, 1995a, p. 601). It will thus be demonstrated, Welsch continues, "that the [...] interparadigmatic [...] entanglements are mostly not hierarchically, but laterally organized. The connection has more the structure of a network than of stratification" (Welsch, 1995a, p. 601).

Against this background the World Wide Web can be interpreted as an eminent medium of transversal reason. The entanglements and transitions analysed in detail by Welsch become media reality in the World Wide Web as electronic links. Welsch's reinterpretation of the classical triad of rationalities as an "effect of family resemblances" (Welsch, 1995a, p. 534) can be illustrated directly with the World Wide Web. In the World Wide Web the classical distinction between the varying types of rationality plays an important role. Thus three different highways can be differentiated on the theoretical level: the (cognitively accented) Information and Commerce Highway, the Education Highway (serving moral-practical aims), and the (aesthetically founded) Entertainment Highway. However, in our practical dealings with the Net - unlike outside the Net - we are aware at all times that these distinctions are introduced by us into a complex framework of hyperlinks whose internal family resemblances constantly shift, and produce different configurations according to different perspectives. Whereas the medium of the book and thinking schooled thereby conceals rather than clarifies these relations, the World Wide Web makes them explicit.

The second basic thesis of Welsch's theory can also be fruitfully deployed for the philosophical analysis of the World Wide Web. Unlike 
the first, this thesis does not relate solely to the mesh of rationalities, but focuses on the faculty of reflecting reason which operates within this mesh. It is this faculty's task to correct "the insufficient self-comprehension and the excessive self-confidence of paradigms" (Welsch, 1995a, p. 673) from which the net of rationality types is composed. Paradigms tend to ignore their position within a net of nets and the relativity resulting from this. They are transfixed by their objects and selfforgetfully obscure the stuctural conditions of their abilities. If they do perceive of their own surroundings, the conditions of their own possibility, and their competitors, then it is mostly in the mode of denial or reprimand. They declare themselves to be the sole true and valid paradigm, make false claims to exclusivity, and tend to an implied absolutism. It is the task of transversal reason to inform the rationalities arising from paradigms of this twofold self-misunderstanding: "Where this twofold explanation is successful, reason's interventions transform the singular paradigms from their merely rational to their reasonable form" (Welsch, 1995a, p. 673).

The World Wide Web confronts us with similar problems. This is already demonstrated by the resistance with which the establishment of a consistently hypertextual practice meets. Every text, every picture, every Web page tends to proclaim itself the centre of the Net. The problem recurs on the technical level: every Web browser, every provider of access to the Net implicitly or explicitly claims to be offering the only true and authentic access to the medium. Even taking a glance at the definition of the whole, the battle over the 'true' World Wide Web dominates. There are firstly those proclaiming this to be the Commerce Net, secondly those in favour of the Education Net, and still others in favour of the Entertainment Highway. Each party of course considers itself the exclusive and sole binding govenor of the Net.

But it is not only the initial problems of radical plurality to which transversal reason reacts, rather the operation of this reason itself can be illustrated with the help of the World Wide Web. On the level of texts, pictures and Web pages, search robots, bookmarks and hotlists function as instantiations of transversal reason in software. Just as transversal reason, these are characterized by "purity, emptiness and superiority" (Welsch, 1995a, 631ff). The Net tools named are independent of content, purely formal structures for the generation of relations. They supply the user with the means required to break through the excessive 


\section{4}

self-estimation of the subsystems and to cast light on the Net's hyperlandscape, i.e. the intertwined connections between Web pages. In the course of the Internet's commercialization, however, efforts are increasing to functionalize search engines for economic purposes. The efforts are made easier by the fact that those offering search engines keep the exact search algorithm secret. Friedrich Kittler has rightly drawn attention to the fact that a central future task for universities will consist of "storing knowledge in a firm-independent manner" (Kittler, 1998, p. 144).

On the level of browser programs, the free availability of shareware versions of various Net browsers and on-line discussion of their advantages and disadvantages contribute to preventing the establishment of a browser-monopoly. Traits of transversal reason can be recognized in this too. The same applies on the level of providers of Internet access: Transversal gateways, through which the various providers are linked to the World Wide Web and to each other, relativize the view of the Net given by a particular provider. It should be emphasized in this that, on all three levels (Web pages, browsers, providers), it is not a matter of just a media realization of a theoretical faculty, but rather of practical demands and concrete tasks which mark the way for future media policies. The necessity of such corrective media policies becomes particularly clear in the face of massive commercialization and monopolization tendencies, such as those being aggressively pushed in the field of browsers by Microsoft and in the providers' field by America Online against the traditional Net culture of plurality.

Thus I come to the third basic thesis of Welsch's book on reason. Philosophy which operates guided by transversal reason is already practice in its core. Transversal reason has no need for a belated application to concrete problems, but is already eminently political in itself. This last aspect of transversal reason also comes into its own in the World Wide Web. Writing and thinking in the Net are of themselves already practical operations. This means, first of all, at a completely fundamental level that they are artisan in character. Writing and thinking in the Net cannot be separated from the creative installation of hyperlinks, from the aesthetic design of Web pages, from the formative work with graphical editor programs and skilled HTML encodement. These are all practical, i.e. artistic-artisanal, operations through which the writer is torn out of the position of the pure observer and bound within concrete 
interactional contexts. Something similar can be said of the way we deal with Net tools. Work with these tools, but also the hypertextual structure itself, leads to the user being referred from the supposedly pure theoretical investigation for which he strives to institutional entanglements, to seemingly remote connections and political contexts. The tools refer you to institutional intertwinements, apparently stray connections, as well as political relationships and at the same time provide a range of instruments allowing users to network themselves in an intelligent and effective manner into virtual and real communities which are addressing these connections and relationships (Lévy, 1997).

Following a relatively long phase of reserve and ignorance toward the media political tasks resulting from the establishment of the Internet as a mass medium, an awareness of the far-reaching politico-practical implications of transmedia network technologies is increasingly prevailing in Europe too. The current state of Internet technology is the result of transdisciplinary scientific Net-use practice, which established itself, having starting at the American elite universities such as Stanford, Harvard or MIT, worldwide in the seventies and eighties. At the centre of this practice are the Enlightenment ideals of openness, transparency, free exchange of information and experimental curiosity. Upholding this tradition, even or precisely in the conditions of an increasingly accentuated commercialization of the Internet, transpires as a central concern for responsible Internet politics. Transversal reason could serve as a philosophical guideline for a pragmatic micropolitics of the sign in that it contributes to helping us see the specific constitution of transmedia technologies and making clear the chances linked with sensible usage of these technologies.

The results of my considerations can be summarized in three points. Firstly, the World Wide Web proves itself to be a genuine medium of transversal reason. Secondly, the concept of transversal reason establishes itself as a basis for a pragmatic media philosophy. Thirdly, the task for this is to demonstrate in detail the relationship between media in the broad, narrow and narrowest sense as a relationship of transversal entanglements. On this basis the media transformations in our understanding of reality which are taking place in the age of digital network technology can be philosophically analysed and pragmatically implemented without speculative bombast.

Translated from German by Andrew Inkpin 


\section{Literature}

Aristotle (1994). Categories and De Interpretatione, translated by John L. Ackrill (Oxford: Clarendon Press.

Bolter, Jay David (1991). Writing Space. The Computer, Hypertext, and the History of Writing, Hillsdale, N.J./London: Lawrence Erlbaum Associates.

Jay David Bolter (1996). Degrees of Freedom, http://www.lcc.gatech.edu/faculty/bolter/index.html).

Bolter, Jay David (1997). Das Internet in der Geschichte der Technologien des Schreibens. In Mythos Internet, ed. Stefan Münker und Alexander Rösler, Frankfurt a.M.: Suhrkamp, pp. 37-55.

Bruckman, Amy (1992). Identity Workshop. Emergent Social and Psychological Phenomena in Text-Based Virtual Reality (http://www.cc.gatech.edu/fac/Amy.Bruckman/papers/index.html\#IW).

Bruckman, Amy / Michael Resnik (1995). The MediaMOO Project. Constructionism and Professional Community. In Convergence. The Journal of Research into New Media Technologies, Spring 1995, vol. 1, no. 1, pp. 94-109 (http://www.cc.gatech.edu/fac/Amy.Bruckman/papers/convergence.html).

Bruckman, Amy (1997a). MOOSE Crossing: Construction, Community, and Learning in a Networked Virtual World for Kids, PhD Dissertation, MIT Media Lab, May 1997 (http://www.cc.gatech.edu/fac/Amy.Bruckman/thesis/index.html).

Bruckman, Amy (1997b): MOOSE Goes to School: A Comparison of Three Classrooms Using a CSCL Environment (http://www.cc.gatech.edu/fac/Amy.Bruckman /papers/csc197.html).

Bush, Vannevar (1945). As We May Think. In Atlantic Monthly, July 1945, vol. 176, pp. 101-108.

Delany, Paul / George P. Landow (eds.) (1991). Hypermedia and Literary Studies, Cambridge, Mass./London: MIT Press.

Derrida, Jacques (1976). Of Grammatology, Baltimore: John Hopkins University Press.

Gibson, William (1984). Neuromancer, New York: Ace.

Goodman, Nelson (1978). Ways of Worldmaking, Indianapolis: Hackett.

Heidegger, Martin (1977). The Age of the World View. In Heidegger, The Question Concerning Technology and Other Essays, New York: Harper \& Row.

Kittler, Friedrich (1998). Universitäten im Informationszeitalter. In Medien-WeltenWirklichkeiten, hrsg. von Gianni Vattimo und Wolfgang Welsch, Munich: Fink, pp. 139-145,

Kjorup, Soren (1978). Pictorial Speech Acts. In Erkenntnis, vol. 12, 1978, pp. 55-71.

Landow, George P. (1992). Hypertext. The Convergence of Contemporary Critical Theory and Technology, Baltimore/London. The John Hopkin University Press.

Lévy, Pierre (1997). Collective Intelligence. Mankind's Emerging World in Cyberspace, New York and London: Plenum. 
Mitchell, William J. (1992). The Reconfigured Eye. Visual Truth in the Post-Photographic Era, Cambridge (Mass.) and London: MIT Press.

Mitchell, William J. (1994). Picture Theory, Chicago: University of Chicago Press.

Mitchell, William J. (1995). City of Bits. Space, Place, and the Infobahn, Cambridge (Mass.) and London: MIT Press (http://www-mitpress.mit.edu/City_of_Bits/).

Morris, Merril / Christine Ogan. The Internet as Mass Medium. In Journal of Communication, vol. 46, no. 1, Winter 1996, pp. 39-50.

Nelson, Ted (1981). Literary Machines, Swarthmore, Pa.: Self-published.

Novitz, David (1977). Pictures and Their Use in Communication: A Philosophical Essay, The Hague: Nijhoff.

Plato (1968). The Republic, translated by Allan Bloom, New York: Basic Books.

Reid, Elizabeth M. (1992). Electropolis: Communication and Community on Internet Relay Chat. In Intertek, 3, vol. 3, Winter 1992, pp. 7-15.

Reynolds, Leighton D. / Nigel G. Wilson (1978). Scribes and Scholars: A Guide to the Transmission of Greek and Latin Literature, Oxford: Clarendon Press.

Rheingold, Howard (1994). The Virtual Community. Homesteading on the Electronic Frontier, New York: Harper.

Rollin, Bernard E. (1976). Natural and Conventional Meaning: An Examination of the Distinction, The Hague and Paris: Mouton.

Rorty, Richard (1967). The Linguistic Turn. Recent Essays in Philosophical Method, Chicago and London: University of Chicago Press.

Sandbothe, Mike (1996a). Digital Entanglements. A Media-Philosophical Analysis of Images, Language, and Writing in the Internet (http://www.uni-jena.de/ms/digi/ digi.html).

Sandbothe, Mike (1996b). Interaktive Netze in Schule und Universität - Philosophische und didaktische Aspekte. In Kursbuch Internet. Anschlüsse an Wirtschaft und Politik, Wissenschaft und Kultur, hrsg. von Stefan Bollmann und Christiane Heibach, Mannheim: Bollmann, pp. 424-433.

Sandbothe, Mike (1998). Transversale Medienwelten. Philosophische Überlegungen zum Internet. In Medien-Welten-Wirklichkeiten, ed. by Gianni Vattimo und Wolfgang Welsch, Munich: Fink, pp. 59-84.

Sandbothe, Mike (1999). Das Internet als Massenmedium. Neue Anforderungen an Medienethik und Medienkompetenz. In Bildung und Erziehung, Bd. 52, 1999, Heft 1, Themenheft: Der pädagogische Diskurs im Internet, S. 65-83.

Sandbothe, Mike (2000a). Media Temporalities of the Internet. Philosophy of Time and Media in Derrida and Rorty. In Cultural Attitudes towards Technology and Communication, a special issue of AI \& Society, ed. by Charles Ess and Fay Sudweeks, Vol. 14, No. 1, London, Springer, 2000 (forthcoming). On-line Publication in: Journal of Computer Mediated Communication, Bd. 4, Heft 2, Dezember 1998, Annenberg School of Communication, University of Southern California (http:// www.ascusc.org/jcmc/). 
Sandbothe, Mike (2000b). Pragmatic Media Philosophy and Media Education. In Enquiries at the Interface: Philosophical Problems of On-line Education. A Special Issue of The Journal of Philosophy of Education, hrsg. von Paul Standish und Nigel Blake, 2000 (forthcoming).

Sandbothe, Mike / Walter Ch. Zimmerli (eds.) (1994): Zeit-Medien-Wahrnehmung, Darmstadt: Wissenschaftliche Buchgesellschaft.

Scholz, Oliver E. (1991). Bild-Darstellung-Zeichen. Philosophische Theorien bildhafter Darstellung, Freiburg/Munich: Alber-Verlag.

Simon, Josef (1995). Philosophy of the Sign, Albany: State University of New York Press.

Turkle, Sherry (1995). Life on the Screen. Identitiy in the Age of the Internet (New York: Simon \& Schuster.

Welsch, Wolfgang (1987). Unsere postmoderne Moderne, Weinheim: VCH Acta humaniora 1987 (4th edition Berlin: Akademie Verlag 1993).

Welsch, Wolfgang (1995a). Vernunft. Die zeitgenössische Vernunftkritik und das Konzept der transversalen Vernunft, Frankfurt a. M.: Suhrkamp.

Welsch, Wolfgang (1995b). Information Superhighway or Highway Number One. In Living. Das Kulturmaganzin, vol. 7, no. 1, 1995, pp. 42-43 (http://www.unijena.de/welsch/papers/Highway.html).

Welsch, Wolfgang (1997). Artificial Paradises? Considering the World of Electronic Media - and Other Worlds. In Welsch, Undoing Aesthetics, London: Sage, pp. 168190.

Welsch, Wolfgang (1998a). Rationality and Reason Today. In Criticism and Defense of Rationality in Contemporary Philosophy, eds. Dane R. Gordon and Józef Niznik, Amsterdam - Atlanta: Rodopi, 1998, pp. 17-31.

Welsch, Wolfgang (1998b). Reason and Transition. On the Concept of Transversal Reason (http://www.uni-jena.de/welsch/papers/Reason.html).

Welsch,Wolfgang / Mike Sandbothe (1997). Postmodernity as a Philosophical Concept. In International Postmodernism: Theory and Literary Practice, hrsg. von Hans Bertens and Douwe Fokkema, Amsterdam: John Benjamins, pp. 75-87.

Wittgenstein, Ludwig (1953). Philosophical Investigations. Third Edition, New York: Macmillan. 